\title{
A questionnaire based study among second year medical students to assess the effectiveness of the usage of Computer Assisted Learning (CAL) as an adjuvant to teaching of pharmacology practicals at Gulbarga institute of medical sciences, Kalaburagi
}

\author{
Harish G. Bagewadi ${ }^{1}$, Savithri Desai ${ }^{2, *}$, Patil Banderao $V^{3}$, Syed Hassan Zahid ${ }^{4}$ \\ ${ }^{1}$ Assistant Professor, ${ }^{2,4}$ Tutor, ${ }^{3}$ Professor \& HOD, Dept. of Pharmacology, Gulbarga Institute of Medical Sciences, Kalaburagi, \\ Karnataka, India
}

*Corresponding Author:

Email: savithridesai@gmail.com

\begin{abstract}
Objective: To evaluate the student's perceptions, and their usefulness Computer Assisted Learning (CAL) as a module alternative to animal experimentation to depict effects of drugs in animals and to receive the feedback regarding pros and cons of this module.

Materials and Method: Second year medical students $(n=155)$ were participated in the study. Computer Assisted Learning was enabled to the students to demonstrate the action of drugs in animals.

Results: Majority of the students expressed their opinion that CAL is an effective and acceptable mode of learning practical aspects of pharmacology. Majority of the $86 \%$ of the students interpret that drug effects can be clearly seen in this CAL method. No interaction with living tissues was expressed as the disadvantage of CAL method by $90 \%$ of the students. Positive feedback was obtained from students regarding the acceptability, reliability, and credibility.

Conclusion: CAL is an interesting and useful educational tool to demonstrate drug effects on living tissues and animals.
\end{abstract}

Keywords: CAL, Pharmacology, Teaching, Drug effects in animals.

\section{Introduction}

Pharmacology is the science of drugs. In a broad sense, it deals with the interaction of exogenously administered chemical molecules with living systems, or any single chemical substance which can produce a biological response is a drug. ${ }^{1}$ Integration of Pharmacology subject along with physiology, molecular and cell biology and its applied aspects enables sound clinical practice in treating many diseases.

Learning pharmacology at undergraduate level enables students to learn basic concepts. i.e. important pharmacological definitions, pharmacokinetics, pharmacodynamics, loading dose, maintenance dose, bioavailability, half-life, kinetics of elimination, enzyme inducers, enzyme inhibitors, mechanism of drug action. Apart from group discussions, tutorials, audio-visual aids, quiz's, bed side oriented learning of clinical pharmacology, still practical exercises serve as integral areas of pharmacology curriculum. practical exercises like pharmacy practical's, interpretation of drug effects through analyzing graphs and charts, prescription are assets through which learning pharmacology can be imparted. ${ }^{2}$ Exercises like demonstrating the effect of drugs on isolated tissues or intact animals enables students to learn the theoretical concepts effectively and helps them to retain longer time. ${ }^{3}$ For the sake of research and development, the usage of animals becomes the dependable one and pivotal role to conduct pre-clinical studies, calculating human equivalent dose, therapeutic index.it becomes inevitable. But, learning pharmacology using animals these days has become difficult because of ethical concerns. ${ }^{4}$ Unnecessary harming or scarifying of the animals during laboratory based practical's using animals can be easily replaced by Computer Assisted Learning (CAL). ${ }^{5}$ Medical education department and the concerned regulators across the globe have been constantly working on this to give reliable solution to this. Recently, the National authority that governs medical education in India, the Medical Council of India (MCI) has framed guidelines insisting that at undergraduate level, animal experiments need not be performed and instead of it, by replacing it with usage of CAL should be substituted. ${ }^{6}$ Studies are done by leaps and bounds to ascertain CAL as a teachinglearning module. ${ }^{7,8}$ However, many studies regarding its effectiveness and validity are not illustrated. In the earlier years animal experiments played key role in teaching- leaning of pharmacology-practical. Because of ethical concerns, cost of maintained of animal houses, usage of animals for teaching purposes these practical demonstrating experiments have taken back seat. In the authors' personal experience it was observed that many students were not able to understand the theoretical concepts of autonomic nervous system like regulation of body system, involvement of receptors, their stimulation, blockade, over activity not accompanied by easy understandable practical demonstrations, learning modules and their application.

Previous studies have inferred that computer simulation exercises are more use full, easy to learn and time saving as well when compared to earlier laboratory 
based animal experimentation. In these studies, students' feedback regarding CAL was gathered. ${ }^{7,8}$ In the present study, data on the psychometric and logistic characteristics of an under-graduate pharmacologypractical curriculum learned through CAL is revisited. Students' knowledge was compared following conventional and CAL modes of teaching and learning. Previous animal experimentation faced many problems like lesser availability of animals for experiments, lack of trained laboratory personnel and ethical concerns regarding the use of animals for teaching purposes. Animal experiments done with usage of CAL also encounter drawbacks like variability in tissue response, inexperience and lack of competence associated with early learning phases for undergraduate students. However, CAL has favorable advantages like it is more flexible, convenient, and easier to perform and user friendly. Drug effects can be easily visualized clearly. The objective of this study was to assess the effectiveness of CAL in students learning and understanding of practical's of pharmacology.

\section{Materials and Method}

The present study was conducted at department of Pharmacology, Gulbarga institute of medical sciences, Kalaburagi. Prior permission was obtained from institutional ethics committee before the conduct of the study. The study was performed in 2nd year MBBS undergraduate medical students $(\mathrm{n}=155)$. Conventional teaching, using blackboard and audiovisual aids, covering topics of autonomic nervous system was conducted in theory classes. Practical's depicting the mechanism action of drugs was taught to students by means of charts, graphs. Later, Each CAL demonstration was done after the practicals were taught by conventional methods. CAL experiments were taught during practical sessions using available software (ExPharm T1.00 for windows. Experiments included were 1. Effect of drugs on rabbit's eye; 2. Effect of drugs on isolated frog's perfused heart; 3. Effect of drugs on dog's BP; 4. Effect of drugs on isolated rectus abdominus muscle. It was announced that a test on what the students understand would be conducted, to serve as a stimulus for them to observe attentively what was being projected. The acceptability, advantages and disadvantages of using CAL as an educational tool were assessed after each session. The questionnaire was obtained from the previous study conducted by A. Kuruvilla et al. ${ }^{9}$ and modified by the department faculties with the option of yes/no were given to the students in each session. At all the difficult levels students were encouraged and allowed to redo the steps by repeated administration of the drugs. The effects of various drugs were demonstrated by observing the response on graph paper. In this session the students were asked to list the advantages and disadvantages of CAL as an educational tool for practical classes in pharmacology (open ended questions) and to give their feedback. For the purpose of free expression of ideas, wills and to avoid bias, anonymity, students were asked to omit their names while answering these questions.

\section{Statistical Analysis}

Data was analyzed and presented as counts and percentages. The chi-square test and unpaired t test was used to compare the difference in correctness for each question. All results attained were entered in Microsoft excel and the statistical calculations were executed using Graph Pad Instat. The p value $(\mathrm{p}<0.05)$ is considered to be statistically significant.

\section{Results}

In (Table 1) it is observed that in all practical exercises, student's scores were statistically significant higher in simulator based learning when compared to teaching by conventional method. In the questionnaire given to students in the session the acceptability of CAL as a method of demonstrating drug effects is clearly shown. Majority of the students opined that CAL has more advantages such as Exercises difficult to be conducted in the laboratory can be demonstrated using CAL; Experiments can be observed repeatedly without loss of animals in (Table 2). The disadvantages enlisted are Variations in response as observed in living tissue cannot be observed in (Table 3). Feedback obtained from the students is presented in Fig. 1.

Table 1: Percentage of student's scores

\begin{tabular}{|c|l|c|c|c|}
\hline S. no & \multicolumn{1}{|c|}{ Practical exercises } & $\begin{array}{c}\text { Conventional } \\
\text { Module of learning }\end{array}$ & $\begin{array}{c}\text { Computer } \\
\text { Assisted learning }\end{array}$ & $\begin{array}{c}\text { P - } \\
\text { value }\end{array}$ \\
\hline 1 & $\begin{array}{l}\text { To demonstrate the effects of various } \\
\text { drugs on rabbit's eye }\end{array}$ & $58.2 \%$ & $90.4 \%$ & $<0.05$ \\
\hline 2 & $\begin{array}{l}\text { To elucidate the effects of various } \\
\text { drugs on Langendorff's heart } \\
\text { preparation }\end{array}$ & $56.5 \%$ & $83.7 \%$ & $<0.05$ \\
\hline 3 & $\begin{array}{l}\text { To demonstrate the effects of various } \\
\text { drugs on dog's blood pressure }\end{array}$ & $62.7 \%$ & $87.1 \%$ & $<0.05$ \\
\hline 4 & $\begin{array}{l}\text { To demonstrate the effects of various } \\
\text { drugs on isolated frog's rectus } \\
\text { abdominus muscle preparation }\end{array}$ & $58.4 \%$ & $92.6 \%$ & $<0.05$ \\
\hline
\end{tabular}

IP International Journal of Comprehensive and Advanced Pharmacology, April-June, 2018;3(2):35-38 
Table 2: Student's opinion on advantages of using CAL module:

\begin{tabular}{|c|c|}
\hline Statement & Response \\
\hline 1. Drug effects can be visualized clearly- & $86 \%$ \\
\hline $\begin{array}{l}\text { 2. Exercises which are difficult to be demonstrated in the laboratory } \\
\text { can be overcome easily by usage of CAL- }\end{array}$ & $88 \%$ \\
\hline $\begin{array}{l}\text { 3. Majority of the students can observe, learn the experiments at the } \\
\text { same allotted time - }\end{array}$ & $85 \%$ \\
\hline $\begin{array}{l}\text { 4. Experiments can be observed repeatedly many number of times } \\
\text { without loss of animals or harming them which increased our } \\
\text { long term retention of practical's learning. }\end{array}$ & $94 \%$ \\
\hline
\end{tabular}

Table 3: Student's opinion on disadvantages of using CAL module:

\begin{tabular}{|c|c|}
\hline Statement & Response \\
\hline 1. Experiments are programmed with prefixed doses & $44 \%$ \\
\hline 2. Lack of interaction with live animals- & $90 \%$ \\
\hline $\begin{array}{l}\text { 3. Biologic variations to dug responses as observed in living tissue } \\
\text { could not be seen. }\end{array}$ & $85 \%$ \\
\hline $\begin{array}{l}\text { 4. Handling of the computers to execute the CAL learning requires } \\
\text { training and expertise. }\end{array}$ & $62 \%$ \\
\hline
\end{tabular}

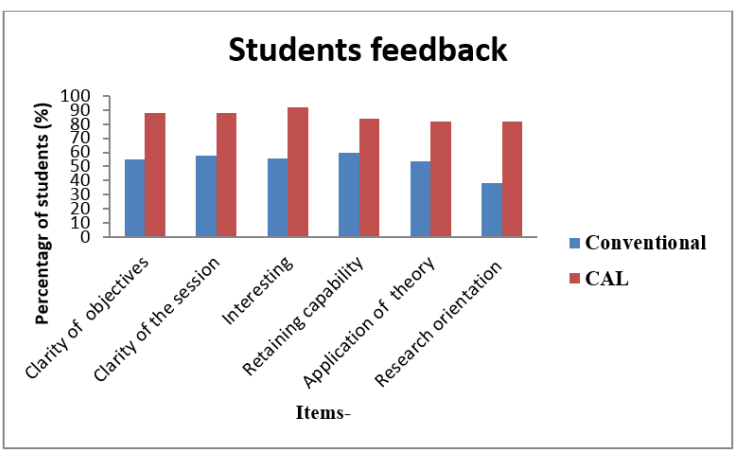

Fig. 1: Students feedback

\section{Discussion}

Our present study interprets the observations and practical considerations on the use of CAL to demonstrate drug effects in animals and in isolated tissues. It is clearly visible from our study that, drastic increase in mean score and number of students scoring more than $50 \%$ shows the superiority of CAL over conventional teaching as an educational module.

Students get demotivated when they are not able to set up practical experiments or when they are not able to interpret the graphs or charts due to their not enough preparation on learning and not able to recollect the subject. But, in contrast, when students engaged in learning the practicals via usage of CAL they were in better position in analyzing, understanding, applying the learned theory while doing practicals. Because at each step students could stop and redo that step of the experiment again and again till he understand it. This exercise played vital role in extracting their knowledge from lectures and textbooks. Moreover, the enthusiasm, towards the computer assisted learning makes students getting absorbed in the sea of learning the things. ${ }^{(8)}$ Practical exercises in pharmacology learned by this
CAL module attain good outcomes. Handling an animal and dissecting it helps to attain the psychomotor skill of a student. But, all the experiments to be carried out by the all the students "first-hand" becomes very difficult practically. When our goal is to make students to attain the observational, analytical and interpretative skills of a student, as these objectives are mainly concerned to the cognitive do-main. It is feasible for a departmental staffs to demonstrate these experiments by CAL and let the students observe the results and interpret them. Computer Assisted Learning can be very handy in such a setting. CAL defiantly helps in attaining the cognitive domain in students rather than psychomotor skill of the students. CAL will also help in learning by great enthusiasm, long term memory to the students. Numerous steps are being taken by faculties towards enriching the teaching and learning modalities to benefit the students. ${ }^{10-13}$ it is in this context that this CAL way of teaching was adopted as an adjuvant in teaching practical's of pharmacology. In CAL mode of learning, students get exposed to self- directed active learning process. But this calls for availability of computers to every student. While this is an ideal learning method with CAL software, many departments and institutions in our country may not opt for it due to money-constraints. Therefore we used this as a demonstration to the whole class. Small group teaching with simultaneous discussion may become effective method for such demonstrations. Our feedback shows that students appreciated this as a welcome change to practical sessions involving demonstrations, routinely conducted in the laboratory. Since these students have been exposed to both methods (faculty conducted conventional method of teaching and also the CAL) their observations are valid and relevant. Dependence on computers and their expertise arising during practicals are possible disadvantages of this method. It 
is clear from this study that CAL software can be used as an acceptable method of teaching practical pharmacology demonstrations to students. Many studies have highlighted the beneficial role of CAL. ${ }^{(14-16)}$ In conclusion; this study shows that CAL is an effective mode of teaching pharmacology to MBBS students. Available software can be used in formative and summative assessment of the students.

Students positive feedback, their enthusiasm in learning pharmacology practical's through CAL is acceptable and may be used as an adjuvant to teaching pharmacology practical's in future.

\section{References}

1. Rivera SM, Gilman AG. Drug Invention and the Pharmaceutical Industry. In: Brunton LL, Chabner BA, Knollman BC, editors. The pharmacological basis of therapeutics. 12th ed. New York: McGraw-Hill Medical 2011; p. 3-16.

2. Lisha J. John. A review of computer assisted learning in medical undergraduates. J Pharmacol Pharmacother 2013; 4: 86-90.

3. Govindaraja C, Jaiprakash H, Annamalai C, Vedhavathy SS. Computer assisted learning: Perceptions and knowledge skills of undergraduate medical students in a Malaysian medical school. National Journal of Physiology, Pharmacy and Pharmacology 2011;1:63-7.

4. Solanki D. Unnecessary and cruel use of animals for medical undergraduate training in India. J Pharmacol Pharmacother 2010;1:59.

5. Badyal DK, Desai C. Animal use in pharmacology education and research: The changing scenario. Indian $J$ Pharm 2014;46:257-65.

6. Medical Council of India (2014). Notification, New Delhi, the 18 March 2014. No. MCI-34(41)/2013Med./64022. In The Gazette of India, Part III, Section 4, No. 19. New Delhi, India: Government of India Press.

7. Vadivelan R, Santilna KS, Elango K, Sirisha S. Alternatives to animals experimentation in teaching pharmacology: Computer assisted learning techniques in pharmacy curriculum; Indian J Physiol Pharmacol 2015;2:70-3.

8. Kuruvilla A, Ramalingam S, Bose AC, Shastri GV, Bhuvaneshwari A, Amudha G. Use of computer assisted learning as an adjuvant to practical pharmacology teaching: Advantages and limitations; Indian J Pharm 2001;33:272-5.

9. GR S, Kamath L, R JC. Reassessment of dispensing pharmacy and animal experiments in undergraduate practical pharmacology curriculum: feedback from students. Int J Basic Clin Pharmacol 2016; 5:285-92.

10. Dahanukar SA. Practical programme for MBBS students. Indian J Pharmacol 1999;31:380-2.

11. Bhavsar VH, Vajpeyee SK, Joshi NJ, Mistry SD, Kantharia ND, Sharma AK et al. Training during practical pharmacol-ogy sessions for undergraduate medical students: An ex-perience with a modified teaching programme. Indian J Pharmacol 1999;31:17686.

12. Bapna JS. Experience in teaching rational drug use. Indian J Pharmacol 1993;25:2-4.

13. Kuruvilla A, Ernest K. Patient oriented problem solving sys-tem of teaching pharmacology. Indian J Pharmacol 1994;26:185-7.

14. Hardin L, Patrick TB. Content review of medical educational software assessments. Medical Teacher 1998;20:
207-11.

15. Sethuraman KR. Computer assisted learning In: Srinivasa DK, Ananthakrishnan N, Sethuraman KR, Santhosh Kumar, editors. Medical education- principles and practice. Na-tional Teacher Training Centre, JIPMER, Pondicherry. 1995;77-81.

16. Horn LD, Radhakrishnan J, Saini S, Pepper GM, Peterson SJ. Evaluation of a computer program for teaching labora-tory diagnosis of acid-base disorders. Computers in Bio-medical Research 1992;25:562-86. 